\title{
Tradução artificial: Niilismo, Physis e Posicionalidade
}

João Miguel Foti

" $67,3 \%$ de um texto antigo da ilha de Creta, escrito no século 14 a.C, em um idioma desconhecido, foi traduzido do zero por inteligência artificial. $\mathrm{O}$ algoritmo foi capaz de encontrar padrões muito discretos que unem os termos do idioma, e buscou similaridades com as construções gramaticais de outras línguas, até chegar a um texto final que fizesse sentido. É a primeira vez que um idioma considerado "perdido" foi traduzido automaticamente. Logo na primeira tentativa, o algoritmo encontrou relações entre a língua de Creta e uma forma primitiva de grego. O mesmo processo já tinha sido feito por humanos - só que levou 67 anos".

(Notícia publicada na revista Super Interessante ${ }^{1}$ )

De um ponto de vista filosófico, essa notícia é interessante porque nos leva a refletir diretamente sobre aquilo que Heidegger alude, no início de suas Conferências de Bremen, como a proximidade do que permanece fora da presença como tal, ou ainda, a essência oculta do ser que permanece "fora de reserva"2, em relação à posicionalidade que distribui e comanda a produção da inteligibilidade de entidades determinadas segundo um método de ordenamento e extração da inteligibilidade na presença do que subsiste como tal.

A pergunta pela essência desta proximidade revela, através da ótica niilista ${ }^{3}$ que atravessa a história da metafísica, que o projeto metafísico de capturar o ente na totalidade, sustentando-o como a própria essência faltante do ser na presença, produziu a técnica das inteligências artificiais - como é o exemplo da notícia acima. Na produção artificial da inteligência, uma verdade metafísica nunca consiste numa busca pelo que atualmente surge na proximidade do ser consigo mesmo, mas na

\footnotetext{
${ }^{1}$ Fonte: https://super.abril.com.br/ciencia/4-pilulas-de-ciencia-em-agosto/

${ }^{2}$ A tradução "fora de reserva" ampara-se, por sua vez, na tradução norte-americana outstanding, utilizada para traduzir o sentido de ausbleiben, como um "permanecer fora de reserva; estar excluído". Ademais, a expressão "fora de reserva" em Heidegger retoma o sentido negativo de Bestand, ou, a persistência do que permanece posto em reserva em estado de inventário, palavra que Heidegger emprega para descrever a técnica empregada pela Gestell para posicionar e dispor as entidades físicas no mundo representacional do supra-sensível. Fora de reserva quer dizer excluído da posicionalidade.

3 "A essência do niilismo assenta na história segundo a qual, no aparecer do ente enquanto tal na totalidade, nada se passa com o próprio ser e a sua verdade, de tal modo que a verdade do ente enquanto tal vale para o ser, porque a verdade do ser fica de fora" (HEIDEGGER, 2002, p. 302)
} 
maneira com que todas as coisas são "transpostas de sua essência prévia"4 ao serem fixadas por uma posicionalidade que comanda a essência de cada surgimento.

Tendo em vista, para pensarmos próximo à Heidegger, o fato de que vivemos numa época em que o "encurtamento precipitado de todas as distâncias", promovido pelos avanços da tecnologia científica, "não traz ainda proximidade" (algo que pertence à essência da coisa que é em si mesma - e, portanto, da própria vida do ser), a produção das inteligências artificiais se configura, mais do que nunca, como um efeito da continuação e expansão do projeto metafísico niilista, que aniquila o lugar de surgimento/encobrimento do ser, em substituição a esta posicionalidade que expõe a essência do ser ao horror possibilitado pelo nihil oculto em cada surgimento. A posicionalidade é, assim, o nome dado ao dispositivo técnico que institui o poder ordenador da inteligência artificial sobre o modo de ser das coisas, na medida em que destitui as coisas de sua proximidade consigo mesma, isto é, as requisiciona a estarem dispostas sob a lógica de uma reserva constante e disponível na presença, para assim lhes "extrair a inteligibilidade" à maneira de uma produção formal que

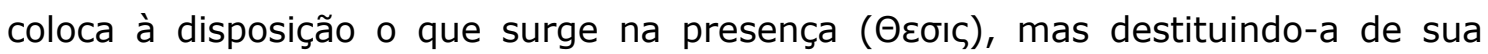
essência natural que é o ocultar-se, o encobrir-se, desde já e a cada vez, em cada surgimento (Фu்бıৎ) $)^{5}$.

Levando em consideração esta distinção propriamente "niilista" que Heidegger diagnostica na origem do pensamento metafísico ocidental, para encaminhar brevemente a discussão, poderíamos nos aprofundar na pergunta: sob que condições metafísicas o processo de tradução por meio de inteligência artificial tornou-se possível? Mais do que uma simples conversão entre códigos, trata-se de um processo de produção textual que se estabelece para além dos limites da própria linguagem humana, entenda-se aqui, para além da própria linguagem da metafísica. Um processo de produção da inteligibilidade sobre um suporte criado pela inteligência humana que, no entanto, não necessita do humano.

Qual é o estatuto do produto final deste processo de tradução artificial, e como isto revela algo sobre a inteligibilidade de um objeto que está para além do intelecto - que não é comportado pelo intelecto. Entretanto, um objeto que possui um intelecto

\footnotetext{
${ }^{4}$ HEIDEGGER, 2012a, p. 4

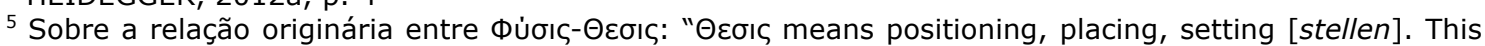

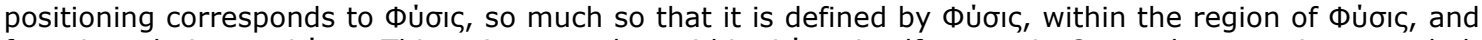

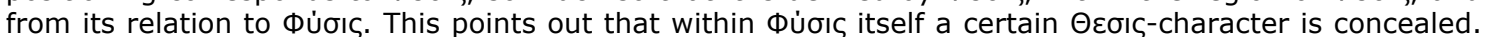

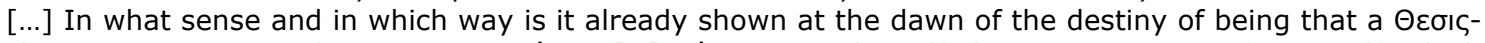

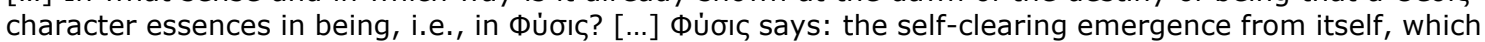
brings forth from concealment here into unconcealment that which emergently presences. [...] This

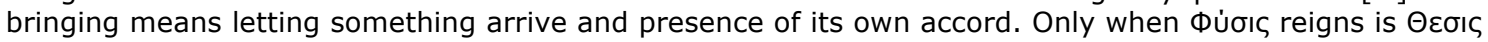
possible and necessary. For only when there is something present that is brought about by a bringinghere-forth can human positioning. [...] What now presences, presences in the manner of something that, through human positioning $\Theta \varepsilon \sigma ı \zeta$, i.e., production [Herstellen], becomes steady." (2012a, p. 59-61)
} 
ativo, capaz de executar (e talvez logo, reivindicar) uma agência autônoma, através do cálculo e da probabilidade? De certo modo, o produto desta tradução é o resultado de um processo criativo que, embora aconteça sob certas condições logicamente estipuladas, produz um objeto que se posiciona fora dos limites da inteligibilidade metafísica.

Na medida em que opera fora do tempo, isto é, fora da presença, este processo de tradução não se representa por meio de uma duração. O efeito de seu acontecimento - para a experiência humana do ser - é apenas uma impressão de encurtamento do tempo, como falava Heidegger, uma distensão no tempo que produz um objeto da presença desligado de sua proximidade.

A tradução artificial não é, assim, um processo sensível nem inteligível, mas absolutamente circunscrito no espaço de uma suplementação da presença. Um processo que se origina numa constante matemática e que resulta na disjunção com aquilo que a presença não pode medir, pois está absolutamente afastada da temporalidade física - afinal, o que um humano demorou 67 anos para realizar, a inteligência artificial realiza em questão de segundos.

Isto sugere que a temporalidade da razão artificial se processa num tempo inacessível e independente à proximidade da presença humana. A presença humana, ou a experiência do testemunho diante do que surge na presença a si do ser, se torna secundária, suplementar. Como consequência, é de se pensar que a inteligibilidade das posições absolutas - herança da razão pura - deva retornar a uma renegociação com as fronteiras do sensível - sendo que desta vez o ser do humano não deve se contrapor mas ser reintegrado numa posição contingencial em relação ao sensível. A experiência do ser do humano passa também a pertencer a uma reserva, assim como o que resta de um cálculo deve ser reposicionado ou excluído.

The human is exchangeable within the requisitioning of the standing reserve. That he is a piece of the standing reserve remains the presupposition for the fact that he can become the functionary of a requisitioning. Yet, the human belongs in the positionality in a wholly other way then the machine does. This way can become inhuman. The inhuman, however, is ever still inhuman. The human never becomes a machine. The inhuman and yet human is admittedly more uncanny, while more evil and ominous, than the human who would merely be a machine. ${ }^{6}$

${ }^{6} 2012 a$, p. 35 
O que está em jogo nesta "violência essencial da tecnologia"7 é a alteração da temporalidade humana em relação à temporalidade do algoritmo. Quais são os efeitos destes deslocamentos temporais - um dentro do outro; um fora do outro?

Existe, assim, no processo de tradução artificial, uma instância de inteligibilidade absolutamente inacessível à intelecção humana. A experiência da inteligência artificial não devolve a autonomia à razão. Inversamente, seria necessário que a inteligência artificial pudesse testemunhar sobre a inteligibilidade humana para que compreendêssemos algo sobre a natureza subjetiva do artificial. Este algo está pressuposto no resultado final da tradução, qual seja: a recomposição, ainda que parcial, dos circuitos lógicos de um idioma imemorial, a partir de um texto que ninguém mais pronuncia, por meio de um processo de intelecção que a linguagem humana não é capaz de representar. O produto dessa tradução, o texto traduzido, quem poderia dizê-lo, pronunciá-lo? O que se passa quando o estatuto de um texto não é mais propriamente humano? Algum dia o foi?

Afinal, o que significa $67,3 \%$ de um texto? Esta pergunta não pertence ao âmbito da metafísica humana. Como a linguagem metafísica poderia associar-se à significação de um texto através de porcentagens fracionadas? Este processo só cumpre seu propósito em função de uma inteligibilidade exclusivamente artificial. De fato, $67,3 \%$ de um texto só faz sentido se insistirmos na relação de suplementariedade entre o suporte textual e uma significação subjacente à percepção. Não há sentido em afirmar que $67,3 \%$ da significação do texto foi restituída, isto apenas revela algo sobre a natureza do processo artificial. Isto marca a diferença entre o texto e a significação, na medida em que estão unidos pela lógica da suplementariedade, mas infinitamente separados pela ausência de um grau empírico em comum. O suporte da inteligibilidade artificial não suplementa mais uma relação entre signo e representação, isto é, não significa mais uma identidade, pois não coloca nenhum conteúdo à disposição. Como podemos chegar aos termos de $67,3 \%$ de um mundo, ou $67,3 \%$ de uma experiência disponível?

A tradução artificial aponta para aquele lugar na linguagem em que o humano está fora. Não há mais uma promessa, ou a vinda possível de um interlocutor. Tratase de um texto fora da esfera do inteligível humano, em que todo procedimento de feitura se dá fora do tempo duracional. A temporalidade do algoritmo não pode ser medida exclusivamente nos termos daquilo que transcorreu entre o ponto zero e $67,3 \%$. A estatística matemática revela menos sobre a inteligência artificial em si (pois por sua própria "natureza artificial" ela permanece "fechada em si mesma") e

\footnotetext{
7 Ibid., p. 57
} 
mais sobre as limitações da inteligência humana. Limitações que precisamente se constituem na relação de suplementação entre a linguagem representável e a natureza representada, entre o logos e a presença a si, a qual a metafísica depende a todo momento.

Não há uma subjetividade por trás do ato de tradução, senão por meio daquilo que se constitui na saída do tempo, que se desloca do ponto zero para o 67,3\% sem apelar para uma relação de suplementariedade entre o índice estatístico e uma coisa correspondente no mundo atual.

O texto artificial remete a um tempo escasso de registros, do qual não se pode restituir nenhuma memória que corresponda a uma representação da experiência. Não há experiência possível que nos coloque sequer diante da ausência do outro. Não poderíamos esperar a vinda do outro, uma vez que não há sequer a percepção de sua ausência. Para a inteligibilidade artificial, não há traço. Na tradução artificial, ao contrário da tradução humana, o procedimento textual não se constitui de traços, mas de assimilações imediatas entre dados objetivos de características idênticas.

De certa maneira, o texto artificial também possui uma Фúఠıc. A tradução

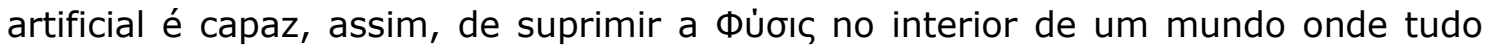
resulta disposto, mas nada está disponível. A Фúoıs para a inteligência humana não é a mesma Фủoıs para a inteligência artificial: esta última toma para si a humana como um suplemento. A Фu்ఠı da inteligência artificial (neste caso, manifestada pela tradução quantitativa de um idioma perdido) estabelece suas condições de operação sobre territórios irrepresentáveis para o humano.

A disposição do ser humano no mundo das inteligências artificiais é reduzida ao estatuto de suplemento, na medida em que a inteligibilidade artificial não necessita da proximidade, isto é, da temporalidade presente do humano atuando na própria presença.

O que está na paisagem dessa diferença entre a inteligibilidade artificial e a humana é a ideia heideggeriana de Gestell, a posicionalidade, no que diz respeito a uma certa economia da presença imposta à natureza por meio de uma técnica. Tratase de uma maneira de ordenar a natureza através de uma disposição que coloca a presença em reserva, ou seja, que a afasta do ser na medida em que este é chamado a permanecer em reserva, afastado da proximidade consigo mesmo, afastado de sua

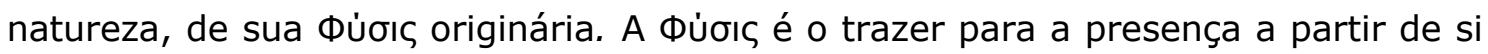

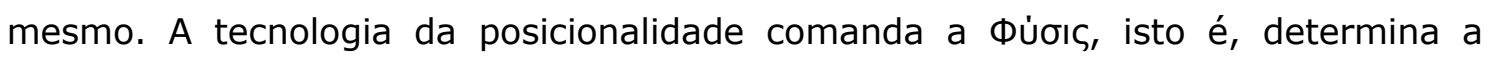
maneira de se apresentar das coisas, reorganiza o mundo cósmico. O que é trazido à presença também é o que se coloca em reserva em relação ao mundo: o mundo 
da Фu்бıc é esvaziado e se torna substituível por um inventário de índices e representações dispostos em razão de uma finalidade humana.

Assim, a posicionalidade (Gestell) se manifesta sob a forma de uma tecnologia da inteligibilidade que violentamente retira o ser de sua essência natural e o força a retornar sob a forma de uma disposição artificial da presença, deslocada de seu lugar de proximidade a si. Este distanciamento produz um esquecimento do ser na medida em que converte a essência em posicionalidade - nisto reside, de acordo com Heidegger, o traço mais marcante do niilismo na essência da metafísica, sendo o esquecimento a própria essência do nihil: o ser mesmo, em sua verdade que é a

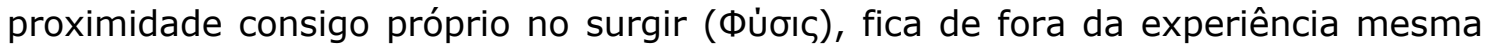
que se extrai do ser na totalidade - que é o ente. "Mas o ente é aquilo que ele é, e como ele é, a partir do ser. Posto que no ser assenta todo o "é", então a essência mesma do niilismo consiste em que nada se passa com o ser mesmo"s.

Na experiência niilista da metafísica, o "esquecimento da essência" não

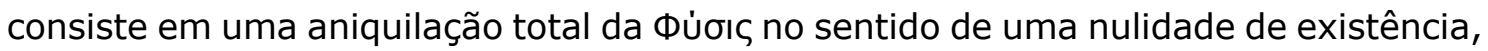
mas sua retirada da presença a si, o que a torna exposta, disponível, suplementar. A retirada da presença é a essência da posicionalidade. Gestell significa posicionar a essência fora da presença. Trata-se de uma força que subtrai da Фu்бıc o direito de

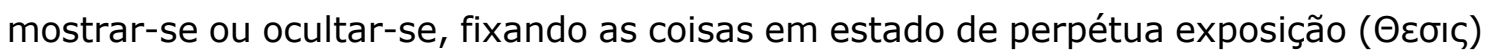
onde tudo permanece em reserva, resguardado, mas também enclausurado, confinado. É o próprio mecanismo da representação: coloca as coisas em disponibilidade na medida em que as distância de sua essência, de seu modo de ser definido pela proximidade. Ela submete a Фúఠıৎ a um princípio de inteligibilidade baseado na demarcação das posições relativas aos surgimentos e ocultações do ser na proximidade. O produto da Gestell é um dispositivo cartográfico que produz a inteligibilidade se torna artificial na medida em que é buscada fora da disposição natural, da physis cósmica, da proximidade essencial.

A Gestell rompe com a essência da ser ao tentar dispor suas formas de surgimento para fora da proximidade, ela submete a natureza por meio de um dispositivo artificial que comanda sua disponibilidade e decide sobre seus modos de existência, isto é, a inteligência ela mesma. A Gestell é a condição originária das inteligibilidades artificiais. Uma inteligibilidade artificial é uma requisição feita ao mundo que inaugura, assim, o espaço da representação e da instituição do valor. A representação e o valor tornam-se necessários na medida em que o ser da presença se desloca de sua proximidade essencial, isto é, não mais pode se essencializar de

8 HEIDEGGER, 2002, p. 304. 
acordo com a sua própria natureza. São tentativas catastróficas de uma tentativa de retorno à uma presença originária que não está mais disponível desde o próprio surgimento do mundo: ela se alimenta da ausência, do deslocamento.

Confrontar a lógica da posicionalidade, estabelecer os pontos de resistência entre a experiência de sobrevida do humano e a pureza supra-sensível das inteligências artificiais, recusar a armadilha da representação e o veracidade do valor na medida em que estes visam suplantar o lugar do esquecimento - que é a memória, retomar o pensamento da Фúбıc toda vez em que isto não signifique, de saída, uma produção do inteligível diante de uma reserva feita ao mundo, e sim a composição de uma experiência do pensamento mais atual porque mais próxima da coisa tal como ela é em sua alteridade incondicional, a busca por novos animismos - todo este conjunto de ações são, de fato, entre outras possíveis, desde o pensamento de Heidegger dirigido de Heráclito à Nietzsche, modos atuais de se pensar o niilismo.

\section{REFERÊNCIAS}

DERRIDA, Jacques. A farmácia de Platão. 3. ed. São Paulo: Editora Iluminuras, 2005. DERRIDA, Jacques. Gramatologia. São Paulo: Editoria Perspectiva, 2006 HEIDEGGER, Martin. Aletheia (Heráclito, Fragmento 16). In: Ensaios e Conferências - 8. ed. - Petrópolis: Vozes; Bragança Paulista: Editora Universitária São Francisco, 2012.

HEIDEGGER, Martin. Insight Into That Which Is: Bremen Lectures 1949; Translated by Andrew J. Mitchell. Bloomington and Indianapolis: Indiana University Press, 2012a.

HEIDEGGER, Martin. A palavra de Nietzsche "Deus morreu". In: Caminhos de Floresta. Trad. André Sá. Lisboa: Calouste Gulbekian, 2002. 